\title{
Structural and Morphological Changes in Human Dentin after Ablative and Subablative Er:YAG Laser Irradiation
}

\author{
Horieh Moosavi', Sajedeh Ghorbanzadeh' ${ }^{2}$ Farzaneh Ahrari $^{3^{*}}$ \\ 'Dental Material Research Center, School of Dentistry, Mashhad University of Medical Sciences, Mashhad, Iran \\ ${ }^{2}$ School of Dentistry, Mashhad University of Medical Sciences, Mashhad, Iran \\ ${ }^{3}$ Dental Research Center, School of Dentistry, Mashhad University of Medical Sciences, Mashhad, Iran
}

\author{
*Correspondence to \\ Farzaneh Ahrari, DDS, MS; Dental \\ Research Center, School of Dentistry, \\ Mashhad University of Medical \\ Sciences, Mashhad, Iran. \\ Tel: +98-511-8788228 \\ Fax:+98-511-8829502 \\ Email: Ahrarif@mums.ac.ir
}

Published online 27 March 2016

\begin{abstract}
Introduction: This study investigated the influence of Erbium-Doped Yttrium Aluminum Garnet (Er:YAG) laser on microhardness, chemical composition and subsurface morphology of dentin cavity walls.

Methods: Forty sound human premolars were selected and randomly assigned into four groups. Class $V$ cavities were prepared either with an Er:YAG laser (groups 1 and 2; $15 \mathrm{~Hz}$, $250 \mathrm{~mJ}$ for enamel, $10 \mathrm{~Hz}, 200 \mathrm{~mJ}$ for dentin) or with a high speed handpiece (groups 3 and 4). The specimens in groups 1 and 3 served as the control, whereas those in groups 2 and 4 were exposed to subablative laser irradiation following cavity preparation $(10 \mathrm{~Hz}$, $50 \mathrm{~mJ}$ ). After bisecting the specimens, one half was subjected to microhardness assessment and the other half was evaluated by SEM-EDS analysis.

Results: Microhardness was significantly greater in the specimens prepared by both ablative and subablative laser irradiation (group 2) than that of the bur-prepared cavities (groups 3 and 4) $(P<0.05)$. The quantity of calcium ion was significantly greater in cavities prepared by the Er:YAG laser (groups 1 and 2) compared to that of the bur cavities (groups 3 and 4) $(P<0.05)$. Subablative irradiation improved microhardness and weight percentage of calcium ion in both laser and bur cavities, but the difference was not significant compared to that of the relevant control group $(P>0.05)$.

Conclusion: Cavity preparation with an Er:YAG laser could be considered as an alternative to the conventional method of drilling, as it enhances the mechanical and compositional properties of lased dentin, especially when combined by subablative irradiation.

Keywords: Laser; Er:YAG; Cavity preparation; Dental; High speed handpiece.
\end{abstract}

\section{Introduction}

Despite the protective measures adopted, dental caries is still the most common oral disease in all over the world. ${ }^{1,2}$ The growing sugar consumption and the inadequate oral hygiene are considered as the main reasons for the high incidence of dental caries. These factors may also contribute to the formation of secondary caries around restorations. Therefore, searching for a cavity preparation technique that enhances the mineral content of tooth tissue is considered as an issue of interest.

Since the introduction of Ruby laser in 1960, lasers have been applied for different purposes in dentistry. It has been indicated that laser irradiation can enhance the resistance of tooth structure against caries formation and progression through different mechanisms. ${ }^{3-6}$ Although various lasers have been employed for the purpose of caries prevention, erbium family lasers including Erbium-Doped Yttrium Aluminum Garnet, (Er:YAG) and Erbium, Chromium-Doped Yttrium Scandium Gallium Garnet (Er,Cr:YSGG) are the only ones that can be employed for removing dentin and enamel structures. ${ }^{7-9}$ Cavity preparation by the Er:YAG laser provides advantages such as low noise and vibration, and less pain and stress for the patients, but it is more expensive and time-consuming than the conventional technique with rotary instruments.

The wavelength of the Er:YAG laser $(2.94 \mu \mathrm{m})$ is greatly absorbed by water and then by hydroxyl groups in hydroxyapatite, making this laser suitable for thermomechanical ablation. ${ }^{10,11}$ During irradiation, the water content of enamel and dentin experiences sudden heating and vaporization, which leads to the production of microexplosions and ejection of both organic and inorganic components from dental hard structure. ${ }^{10,11}$ Since the energy of Er:YAG laser is mainly absorbed in superficial enamel or dentin tissues, the thermal damage to the pulp or surrounding structures is prevented to a great extent. ${ }^{12,13}$

The use of Er:YAG laser for cavity preparation can affect the mineral content of the tooth, which in turn influences its resistance to further caries formation. ${ }^{14}$ Previous 
studies reported contradictory results regarding the effect of Er:YAG laser with ablative or subablative parameters on resistance of lased substrate to acid attack. Some authors ${ }^{15}$ reported less development of caries lesion around cavities prepared by the Er:YAG laser than around the bur-prepared cavities, while Hossain et $\mathrm{al}^{16}$ demonstrated similar knoop hardness in laser and bur cavities. Regarding irradiation with subablative parameters, Apel et al ${ }^{17}$ demonstrated some increase in acid resistance following subablative irradiation with erbium family lasers, which failed to achieve significance in the statistical analysis, whereas Liu et $\mathrm{al}^{18}$ and Castellan et $\mathrm{al}^{19}$ reported a significant prevention of enamel demineralization. Morphological examination of surfaces treated by the Er:YAG laser revealed roughness and irregularities which provided microretentive patterns $s^{12,20-23}$ and at the cavity walls, there was almost no smear layer. ${ }^{10,20,22}$

Considering the contradictory results of previous authors, the purpose of this in vitro investigation was to determine the influence of ablative and subablative Er:YAG laser irradiation on microhardness, composition and surface morphology of dentin cavity walls and compare the results with that of the conventional method of bur preparation.

\section{Methods}

Sound human premolars extracted before orthodontic treatment were collected and stored in normal saline solution until the time of the experiment. The teeth were cleaned with rubber prophylactic cups and examined visually to discard those with hypoplastic areas or other structural defects. Finally, 40 premolars were chosen and stored in $1 \%$ thymol solution for 1 week.

The sample was then randomly assigned to four groups of 10 each. Class V cavities $2 \mathrm{~mm}$ in width, $2 \mathrm{~mm}$ in height and $1.5 \mathrm{~mm}$ deep were prepared on the buccal cervical areas of premolar teeth either with an Er:YAG laser (groups 1 and 2) or with a high speed handpiece. The specimens in groups 2 and 4 were also exposed to subablative Er:YAG laser irradiation following cavity preparation in order to assess any benefit of using subablative parameters in increasing caries resistance. The cavity area was delimited by a piece of insulating tape with a central hole, made by a punch. The depth of the cavities was controlled by a periodontal probe.

The laser apparatus used was the Kavo Key Laser 2 (KaVo Dental GmbH, Biberach, Germany). The laser operated in noncontact and focused mode and in association with water stream at $1.5 \mathrm{ml} / \mathrm{min}$ flow. The 2051 handpiece was used through a flexible fiber delivery system so that the beam was perpendicular to the irradiated surface. The "very short pulse setting" was chosen throughout the experiment. For enamel ablation, the energy of $250 \mathrm{~mJ}$ was used with pulse repetition rate of $15 \mathrm{~Hz}$, whereas $200 \mathrm{~mJ}$ and $10 \mathrm{~Hz}$ were employed for dentin ablation. The subablative parameters employed were $50 \mathrm{~mJ} / 10 \mathrm{~Hz}$.

After cavity preparation, the roots of the teeth were sectioned $2 \mathrm{~mm}$ below the cementoenamel junction and the crowns were mounted in polyester resin. Then, the teeth were bisected longitudinally in a buccolingual direction through the middle of the prepared cavities using a water-cooled diamond saw. One hemisection of each specimen was used for microhardness assessment and the other one was prepared for examination by scanning electron microscopy (SEM).

\section{Microhardness Assessment}

The tooth sections destined for microhardness assessment were polished alternatively with no. Six hundred to 1200 grit silicon carbide papers to create a smooth surface for increasing the precision of reading. The specimens were then individually fixed in cylindrical plates with wax. A parallelometer was applied to ensure that the surface was kept parallel to the horizontal plane. A Vickers hardness apparatus (Matsuzawa, model MHT2, Japan) was employed to evaluate microhardness of the specimens using a $500 \mathrm{~g}$ load for 20 seconds. Microhardness was assessed at the occlusal, axial, and gingival walls of the cavities at the depth of $30 \mu \mathrm{m}$ from the surface. The Vickers hardness number (VHN) was recorded and the mean value was calculated for each specimen.

\section{SEM-EDS Examination}

One hemisection of each specimen was prepared for SEMEDS analysis. After a standard preparation technique, the specimens were mounted on aluminum stubs, sputter coated with gold and then examined with a Tescan VEGA II scanning electron microscope (SEM; Tescan, Brno, Czech Republic) operating at an accelerating voltage of $15 \mathrm{kV}$. Photomicrographs were taken at different magnifications to indicate subsurface morphological changes. The histochemical analysis was done by energy-dispersive $\mathrm{x}$-ray spectroscopy (EDS) and the weight percentage of calcium ion in each specimen was measured. The EDS measurements were taken from the occlusal, axial and gingival walls of the cavities at the depth of $30 \mu \mathrm{m}$ from the surface, and the mean value was recorded for each specimen.

\section{Statistical Analysis}

The average microhardness and calcium ion quantity obtained from different walls of each specimen was calculated and considered for statistical analysis. The Kolmogorov-Smirnov test confirmed the normal distribution of the data. One-way analysis of variance (ANOVA) was run to detect any significant differences in hardness and weight percentage of calcium ion among the study groups, followed by Tukey post hoc test for pairwise comparisons. The statistical analysis was performed by SPSS version 16.0 (SPSS Inc., Chicago) software and the statistical significance was determined at $P<0.05$.

\section{Results}

Microhardness Assessment

The mean and standard deviation (SD) of microhardness values of the study groups is presented in Table 1. ANO- 
VA showed a significant difference in microhardness among the study groups (Table 1). Tukey post hoc test revealed that microhardness was significantly greater in group 2 (laser application for cavity preparation followed by subablative irradiation) than groups 3 and $4(P<0.05)$, which were prepared by the bur. No significant difference was found in microhardness either between groups 1 and 2 , or between groups 3 and $4(P>0.05)$.

\section{SEM-EDS Assessment}

Comparison of the weight percentage of calcium ion among the study groups is presented in Table 2. ANOVA revealed a significant difference in the quantity of calcium ion among the groups (Table 2). According to Tukey analysis, the quantity of calcium was significantly greater in groups 1 and 2 compared to groups 3 and $4(P<0.05)$. Neither groups 1 and 2 nor groups 3 and 4 displayed statistically significant differences to each other regarding the weight percentage of calcium ion $(P>0.05$, Table 2$)$.

Figure 1 illustrates the SEM images taken from cavities prepared by different techniques. Laser irradiation for cavity preparation caused irregularities and alterations in surface morphology. Fusion areas with less opened dentinal tubules were observed after subablative irradiation in both laser and bur cavities.

\section{Discussion}

The application of Er:YAG laser has been suggested as a suitable alternative to conventional cavity preparation instruments for removing dental caries and tooth tissue. ${ }^{24}$ The outcomes of this study indicate that cavity preparation with the Er:YAG laser instead of rotary instruments can enhance mechanical properties and chemical composition of the lased substrate and possibly increase its resistance against further caries attack.

Table 1. The Descriptive Statistics and the Results of Statistical Analysis for Comparison of Microhardness Values Among the Experimental Groups

\begin{tabular}{lccc}
\hline & Mean & SD & Pairwise Comparison $^{*}$ \\
\hline Group 1 & 708.92 & 73.43 & a, b \\
Group 2 & 742.89 & 108.64 & a \\
Group 3 & 679.13 & 80.69 & b, c \\
Group 4 & 655.32 & 93.14 & b, c
\end{tabular}

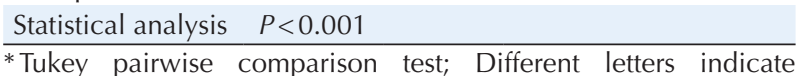
statistically significant differences at $P<0.05$.

Table 2. The Descriptive Statistics and the Results of Statistical Analysis for Comparison of Calcium Ion Quantity Among the Experimental Groups

\begin{tabular}{|c|c|c|c|}
\hline & Mean (Weight \%) & SD & Pairwise Comparison* \\
\hline Group 1 & 29.61 & 2.12 & a \\
\hline Group 2 & 30.53 & 1.36 & a \\
\hline Group 3 & 22.47 & 1.02 & b \\
\hline Group 4 & 22.63 & 2.15 & b \\
\hline $\begin{array}{l}\text { Statistical } \\
\text { analysis }\end{array}$ & $P<0.001$ & & \\
\hline
\end{tabular}

statistically significant differences at $P<0.05$.
Laser absorption in tooth tissue provides thermal effects that influence the structural and chemical properties of dental hard tissues. ${ }^{1,25}$ The heat produced during laser irradiation leads to vaporization, oxidation of organic components, transformation of acid phosphate to pyrophosphate, and reduction of carbonate content. ${ }^{3,4,25,26}$ These changes result in the formation of more stable and less soluble components, which might increase the resistance of irradiated substrate against demineralization. ${ }^{3}$ The blocking of intra and inter spaces of enamel due to heating of the organic matrix has also been suggested as a possible mechanism for caries prevention. ${ }^{5,27}$

Microhardness readings indicate the mineral content of the teeth, and the quantity of calcium ion could be representative for any alteration in the composition of dental hard tissue which affects its permeability and solubility in different media. In the present study, it was found that the quantity of calcium ion was significantly greater in laserthan bur-prepared cavities. Although microhardness of laser cavities was greater than that of bur cavities, but the statistical significance with bur cavities was only obtained when both ablative and subablative parameters (group 2) were employed. The improvement obtained in chemical and mechanical properties of dentin may be related to the vaporization of water and organic components, which increases the percentage of mineral content in the lased substrate..$^{28}$ In the clinical conditions, it is possible that the modifications occurred in Er:YAG laser ablated dentin act against demineralization and caries formation around restorations.

The findings of this study confirmed the outcomes of
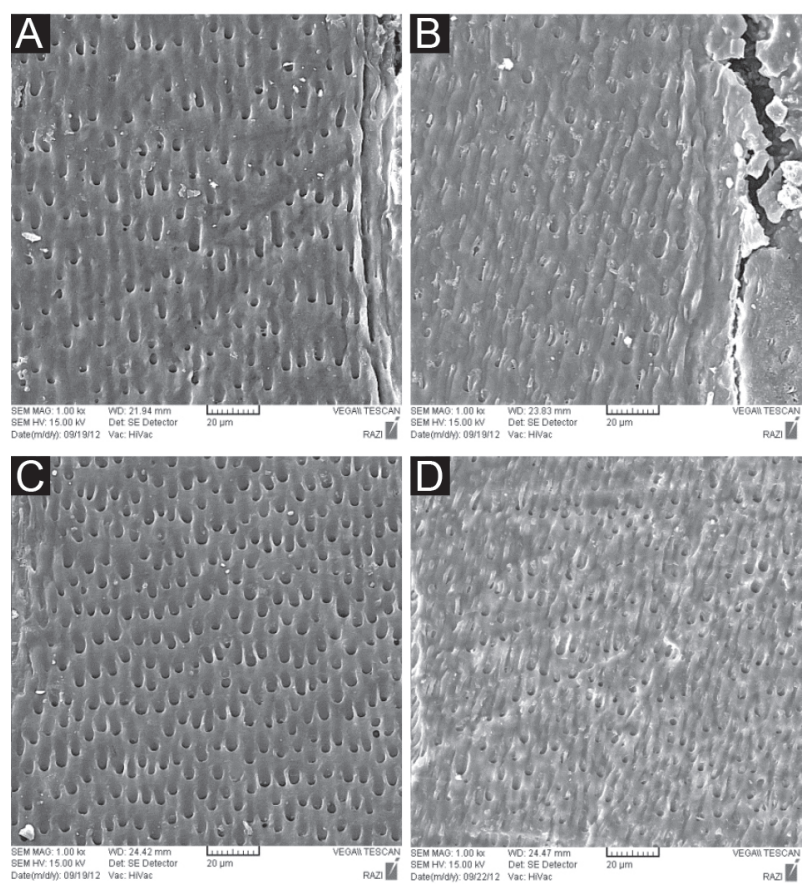

Figure 1. Surface morphology of the cavities prepared by $(A)$ Er:YAG laser, (B) Er:YAG laser followed by subablative irradiation, (C); diamond bur, (D) diamond bur followed by subablative Er:YAG laser irradiation. 
Hossain et $\mathrm{al}^{16}$ who found that the quantities of calcium (Ca weight \%) and phosphorus (P weight \%) of dentin were significantly greater in laser cavities compared to bur cavities. Perito et $\mathrm{al}^{15}$ reported less development of secondary caries around the cavities prepared by Er:YAG laser than around bur-prepared cavities. In contrast, Celik et $\mathrm{a}^{28}$ found that cavity preparation with bur or erbium family lasers did not significantly affect the composition and microhardness of dentin structure. Chimello et $\mathrm{al}^{12}$ reported that microhardness of enamel adjacent to composite resin restorations submitted to high cariogenic challenge was comparable in groups prepared by an Er:AYG laser or a high-speed handpiece. Hossain et $\mathrm{al}^{16}$ found that the knoop hardness of the cavity floors prepared by Er:YAG laser was comparable to that of the conventional bur cavity. Apel et $\mathrm{al}^{29}$ concluded that cavity preparation by means of an erbium laser would offer no benefits in the sense of resistance to secondary caries formation in the clinical situation. The differences observed between the outcomes of this study and those of previous authors could be attributed to the laser parameters employed such as pulse energy and duration, pulse repetition rate, duration of laser irradiation and application of water cooling.

The application of Er:YAG laser with subablative parameters has been attempted as a way to increase caries resistance by induction of chemical and structural changes on the surface without removing tooth tissue. In this study, the highest microhardness and the greatest quantity of calcium ion were obtained when Er:YAG laser was employed for both cavity preparation (ablative parameters) and surface treatment (subablative parameters). Although subablative Er:YAG laser irradiation increased microhardness and quantity of calcium ion in both laser- and bur-prepared cavities, but the difference was not significant compared to that of the relevant control groups. This is consistent with the outcomes of Rodriguez-Vilchis et $\mathrm{al}^{30}$ who found that acid resistance of enamel did not increase as expected following subablative Er:YAG laser irradiation. Apel et $\mathrm{ll}^{31}$ indicated no significant difference in calcium solubility between the specimens irradiated with the subablative Er:YAG and Er,Cr:YSGG lasers and that of the control. Another study demonstrated the formation of cracks following subablative erbium laser irradiation, which might act as starting points for acid attack and thus attenuate any positive effect of laser irradiation on caries prevention. ${ }^{32}$

Some irregularity and modification in surface texture was observed in cavities prepared with the Er:YAG laser compared to those prepared by the high speed handpiece. In both laser- and bur- prepared cavities, the subablative Er:YAG laser irradiation caused dense and compact regions with less open tubules possibly due to the high percentage of tubular blockage or because of the recrystallization that may occur after surface heating. ${ }^{11}$ These alterations may be in accordance with the increased mineral content and enhanced composition of the irradiated dentin, as observed in the present investigation. Other studies also indicated topographical alterations including irregularities, craters and cracks in enamel and dentin specimens treated by Er:YAG or Er,Cr:YSGG lasers. ${ }^{10,11,20-23,30,33}$ The laser settings used in this study were selected in order to produce efficient enamel and dentin ablation, simulating the clinical conditions. Most of the previous studies used lower pulse repletion rates compared to that used in this study, but the number of microexplosions and the rate of ablation are directly dependent on this parameter. ${ }^{34,35}$ Therefore, the use of lower pulse repetition rates may make the cavity preparation a time-consuming process. When using Er:YAG laser with subablative parameters, it is very important to use the lowest energy level because higher energies produce microcracks and damage the peripheral and underlying tissues. ${ }^{18}$ Therefore, subablative irradiation in this study was carried out with a very low energy level.

Considering the promising outcomes of this study, cavity preparation with Er:YAG laser could be considered as a viable alternative to the conventional application of high speed handpiece and burs, which enhances the mechanical and compositional properties of lased dentin, especially when combined by subablative irradiation. However, alterations in surface morphology and calcium ion quantity can affect the adhesion pattern of restorative materials. ${ }^{11,36}$ Therefore, any adverse effect on the bonding interface should be investigated in future studies. Long term studies are also required to elucidate any consequence of the present findings in the clinical situation.

\section{Conclusion}

Under the conditions used in this study: (1) Microhardness was significantly greater in cavities prepared by ablative followed by subablative Er:YAg laser irradiation compared to that of the bur-prepared cavities. (2) The application of Er:YAG laser for cavity preparation caused a significant increase in the quantity of calcium ion compared to that of the bur cavities, indicating enhancement in the composition of lased-dentin.

\section{Acknowledgements}

The authors would like to thank the vice-chancellor for research of Mashhad University of Medical Sciences for the financial support of this project [grant number 88577]. The results presented in this paper have been taken from a DDS student thesis [thesis number 2515].

\section{Ethical Considerations}

This was an in vitro study. The specimens were teeth that had been extracted for orthodontic reasons. Therefore, no ethical code is required.

\section{Conflict of Interest}

The authors declare no conflict of interests.

\section{References}

1. Heravi F, Ahrari F, Mahdavi M, Basafa S. Comparative evaluation of the effect of Er:YAG laser and low level laser 
irradiation combined with CPP-ACPF cream on treatment of enamel caries. J Clin Exp Dent. 2014;6(2):e121-6. doi:10.4317/jced.51309.

2. Ahrari F, Eslami N, Rajabi O, Ghazvini K, Barati S. The antimicrobial sensitivity of Streptococcus mutans and Streptococcus sangius to colloidal solutions of different nanoparticles applied as mouthwashes. Dent Res J (Isfahan). 2015;12(1):44-49.

3. Fowler BO, Kuroda S. Changes in heated and in laserirradiated human tooth enamel and their probable effects on solubility. Calcif Tissue Int. 1986;38(4):197-208. doi:10.1007/bf02556711.

4. Liu Y, Hsu CY. Laser-induced compositional changes on enamel: a FT-Raman study. J Dent. 2007;35(3):226-230. doi:10.1016/j.jdent.2006.08.006.

5. Maung NL, Wohland T, Hsu CY. Enamel diffusion modulated by Er:YAG laser (Part 1)--FRAP. J Dent. 2007;35(10):787-793. doi:10.1016/j.jdent.2007.07.011.

6. Poosti M, Ahrari F, Moosavi H, Najjaran H. The effect of fractional $\mathrm{CO}_{2}$ laser irradiation on remineralization of enamel white spot lesions. Lasers Med Sci. 2014;29(4):13491355. doi:10.1007/s10103-013-1290-9

7. Ahrari F, Basafa M, Fekrazad R, Mokarram M, Akbari M. The efficacy of Er,Cr:YSGG laser in reconditioning of metallic orthodontic brackets. Photomed Laser Surg. 2012;30(1):41-46. doi:10.1089/pho.2011.3088.

8. Ahrari F, Fekrazad R, Kalhori KA, Ramtin M. Reconditioning of ceramic orthodontic brackets with an Er,Cr:YSGG laser. Lasers Med Sci. 2013;28(1):223-228. doi:10.1007/s10103-012-1093-4.

9. Dehghani M, Ahrari F. The effect of surface treatment with Er: YAG laser on shear bond strength of orthodontic brackets to fiber-reinforced composite. J Clin Exp Dent. 2014;6(4):e379-e383. doi:10.4317/jced.51613.

10. 10. Chinelatti MA, Raucci-Neto W, Corona SA, PalmaDibb RG. Effect of erbium:yttrium-aluminum-garnet laser energies on superficial and deep dentin microhardness. Lasers Med Sci. 2010;25(3):317-24. doi:10.1007/s10103008-0618-3.

11. Souza-Gabriel AE, Chinelatti MA, Pecora JD, Palma-Dibb RG, Corona SA. Dentin microhardness and subsurface morphology after Er:YAG laser cavity preparation using different parameters. J Dent Child (Chic). 2009;76(1):58-66.

12. Chimello DT, Serra MC, Rodrigues-Junior AL, Pecora JD, Corona SA. Influence of Er:YAG laser on microhardness of enamel adjacent to restorations submitted to cariogenic challenge in situ. Photomed Laser Surg. 2008;26(4):379385. doi:10.1089/pho.2008.2193.

13. Jahanbin A, Ramazanzadeh B, Ahrari F, Forouzanfar A, Beidokhti M. Effectiveness of Er:YAG laser-aided fiberotomy and low-level laser therapy in alleviating relapse of rotated incisors. Am J Orthod Dentofacial Orthop. 2014;146(5):565-572. doi:10.1016/j.ajodo.2014.07.006.

14. Shahabi M, Ahrari F, Mohamadipour H, Moosavi H. Microleakage and shear bond strength of orthodontc brackets bonded to hypomineralized enamel following different surface preparations. J Clin Exp Dent. 2014;6(2):e110-e115. doi:10.4317/jced.51254.

15. Perito MA, Jorge AC, de Freitas PM, Cassoni A, Rodrigues JA. Cavity preparation and influence of restorative materials on the prevention of secondary caries. Photomed Laser Surg. 2009;27(5):729-734. doi:10.1089/pho.2008.2394.

16. Hossain M, Nakamura Y, Murakami Y, Yamada Y,
Matsumoto K. A comparative study on compositional changes and Knoop hardness measurement of the cavity floor prepared by Er:YAG laser irradiation and mechanical bur cavity. J Clin Laser Med Surg. 2003;21(1):29-33.

17. Apel C, Birker L, Meister J, Weiss C, Gutknecht N. The caries-preventive potential of subablative Er:YAG and Er:YSGG laser radiation in an intraoral model: a pilot study. Photomed Laser Surg. 2004;22(4):312-317. doi:10.1089/1549541041797931.

18. Liu Y, Hsu CY, Teo CM, Teoh SH. Subablative Er:YAG laser effect on enamel demineralization. Caries Res. 2013;47(1):63-68. doi:10.1159/000343573.

19. Castellan CS, Luiz AC, Bezinelli LM, et al. In vitro evaluation of enamel demineralization after Er:YAG and Nd:YAG laser irradiation on primary teeth. Photomed Laser Surg. 2007;25(2):85-90.

20. Kohara EK, Hossain M, Kimura Y, et al. Morphological and microleakage studies of the cavities prepared by Er:YAG laser irradiation in primary teeth. J Clin Laser Med Surg. 2002;20(3):141-147.

21. Navarro RS, Gouw-Soares S, Cassoni A, et al. The influence of erbium:yttrium-aluminum-garnet laser ablation with variable pulse width on morphology and microleakage of composite restorations. Lasers Med Sci. 2010;25(6):881889.

22. Freitas PM, Navarro RS, Barros JA, de Paula Eduardo C. The use of Er:YAG laser for cavity preparation: an SEM evaluation. Microsc Res Tech. 2007;70(9):803-808.

23. Harashima T, Kinoshita J, Kimura Y, et al. Morphological comparative study on ablation of dental hard tissues at cavity preparation by Er:YAG and Er,Cr:YSGG lasers. Photomed Laser Surg. 2005;23(1):52-55.

24. Nishimoto Y, Otsuki M, Yamauti M, et al. Effect of pulse duration of Er: YAG laser on dentin ablation. Dent Mater J. 2008;27(3):433-439. doi:10.4012/dmj.27.433.

25. Ahrari F, Poosti M, Motahari P. Enamel resistance to demineralization following Er:YAG laser etching for bonding orthodontic brackets. Dent Res J (Isfahan). 2012;9(4):47247-7.

26. Cecchini RC, Zezell DM, de Oliveira E, de Freitas PM, Eduardo Cde P. Effect of Er:YAG laser on enamel acid resistance: morphological and atomic spectrometry analysis. Lasers Surg Med. 2005;37(5):366-372. doi:10.1002/ $1 \mathrm{sm} .20247$.

27. Ying D, Chuah GK, Hsu CY. Effect of Er:YAG laser and organic matrix on porosity changes in human enamel. J Dent. 2004;32(1):41-46. doi:10.1016/s03005712(03)00138-6.

28. Celik EU, Ergucu Z, Turkun LS, Turkun M. Effect of different laser devices on the composition and microhardness of dentin. Oper Dent. 2008;33(5):496-501. doi:10.2341/07-127.

29. Apel C, Schafer C, Gutknecht N. Demineralization of Er:YAG and Er,Cr:YSGG laser-prepared enamel cavities in vitro. Caries Res. 2003;37(1):34-37. doi:10.1159/000068228.

30. Rodriguez-Vilchis LE, Contreras-Bulnes R, Sanchez-Flores I, Samano EC. Acid resistance and structural changes of human dental enamel treated with Er:YAG laser. Photomed Laser Surg. 2010;28(2):207-211. doi:10.1089/ pho.2008.2454.

31. Apel C, Meister J, Schmitt N, Graber HG, Gutknecht N. Calcium solubility of dental enamel following sub-ablative Er:YAG and Er:YSGG laser irradiation in vitro. Lasers Surg 
Med. 2002;30(5):337-341. doi:10.1002/lsm.10058.

32. Apel C, Meister J, Gotz H, Duschner H, Gutknecht N. Structural changes in human dental enamel after subablative erbium laser irradiation and its potential use for caries prevention. Caries Res. 2005;39(1):65-70. doi:10.1159/000081659.

33. Rodriguez-Vilchis LE, Contreras-Bulnes R, Olea-Mejia OF, Sanchez-Flores I, Centeno-Pedraza C. Morphological and structural changes on human dental enamel after Er:YAG laser irradiation: AFM, SEM, and EDS evaluation. Photomed Laser Surg. 2011;29(7):493-500. doi:10.1089/ pho.2010.2925.

34. Corona SA, Souza-Gabriel AE, Chinelatti MA, et al.
Influence of energy and pulse repetition rate of Er:YAG laser on enamel ablation ability and morphological analysis of the laser-irradiated surface. $J$ Biomed Mater Res A. 2008;84(3):569-575. doi:10.1002/jbm.a.31335.

35. Ahrari F, Akbari M, Akbari J, Dabiri G. Enamel surface roughness after debonding of orthodontic brackets and various clean-up techniques. J Dent (Tehran). 2013;10(1):82-93.

36. Schein MT, Bocangel JS, Nogueira GE, Schein PA. SEM evaluation of the interaction pattern between dentin and resin after cavity preparation using ER:YAG laser. $J$ Dent. 2003;31(2):127-135. doi:10.1016/s0300-5712(03)00003-4. 